\title{
Use of Rice Straw Ash as Pozzolanic Material in Cement Mortar
}

\author{
Surajit Munshi, Gopinandan Dey, and Richi Prasad Sharma
}

\begin{abstract}
In this paper an experimental study was made on the effects of using Rice Straw Ash (RSA) as a partial replacement of cement in mortar. Control specimens with ordinary Portland cement (OPC) was made and in other specimens cement were replaced with $5 \%, 10 \%$ and $15 \%$ of RSA by weight of cement. Locally available rice straw was burnt to ash in uncontrolled manner in the earthen oven used by the rural people for cooking purpose, which were used in this study. The setting times and compressive strength of that mortar mix using RSA at different percentage of cement replacement was investigated and compared with the control specimen. The tests results obtained shows that setting times are delayed with increased amount of cement replacement and there is enhancement of strength of mortar with certain quantity of replacement of cement with RSA which will lead to reduction of construction cost.
\end{abstract}

Index Terms-Rice straw ash, setting time, compressive strength, mortar.

\section{INTRODUCTION}

For the improvement of the properties of cement mortar and cement concrete or the construction cost to be economic, admixtures are added with the cement mix and these are either naturally occurring compounds or chemicals produced in industrial process. Most of the admixtures are pozzolans. Pozzolan is a powdered material, which when added to the cement in the mix reacts with lime, released by the hydration of the cement, to create compounds which improve the strength or other properties of the concrete or mortar [1].

According to ASTM [2] after chemical analysis if the sum of Iron oxide $\left(\mathrm{Fe}_{2} \mathrm{O}_{3}\right)$, Silicon oxide $\left(\mathrm{SiO}_{2}\right)$ and Aluminum oxide $\left(\mathrm{Al}_{2} \mathrm{O}_{3}\right)$ is more than $70 \%$ then the material would be declared as a Pozzolanic material.

It is observed by many researchers that there is an increase of compressive strength of mortar with the use of pozzolanic materials. The increase in compressive strength could be attributed to the reduced water content, the filler effect, and the higher pozzolanic reaction. The fine fineness of pozzolans had a greater pozzolanic reaction and the small particles could also fill in the voids of the mortar mixture, thus increasing the compressive strength of the mortar [3].

The use of supplementary cementitious materials, such as fly ash, silica fume, and blast furnace slag, in concrete construction is widespread. Supplementary cementitious materials may considerably improve the strength and durability of concrete [4], [5]. A number of relatively new

Manuscript received April 11, 2013; revised June 8, 2013.

The authors are with the Dept. of Civil Engineering, National Institute of Technology Agartala, India (e-mail: surajitm964@gmail.com, gopinita@ymail.com, richisharma.sharma@gmail.com). supplementary cementitious materials, such as rice husk ash, sewage sludge ash, and oil shale ash, have undergone extensive research [6], [7].

The development of natural material cementitious composites to produce building materials for construction is going for many years. India is one of the largest rice producing countries and per capita rice consumption is higher than that in any other countries. There are main three biomass byproduct comes from rice viz. rice straw, rice husk and rice bran. Rice straw, rice husk and rice bran are used as feed for cattle, poultry, fish etc. [8]. In villages people also use rice straw in cooking and other purpose by burning. After burning a huge amount of rice straw, ash is produced and dumped it as waste which creates an environmental problem though some time it is used in the agricultural land.

For decreasing the cost of construction materials and raising environmental concerns, considerable efforts are being taken worldwide to utilize local natural waste and byproduct materials to improve the performance of construction materials. Conventional building materials are beyond the reach of a majority of the world population due to their poor affordability. Rice straw is one of the major agricultural byproduct and available all parts of the world. During growth, rice plants absorb silica from the soil and accumulate it into their structures. It is this silica, concentrated by burning at high temperatures removing other elements, which make the ash so valuable. Amongst the agricultural waste, rice straw has a very high potential for the production of very effective secondary raw material. It is mainly due to its random availability, very high silica content and relatively low cost. After burning rice straw and husk in controlled temperature and duration using properly small plants, $14.6 \%$ and $22 \%$ of mass rice straw and husk respectively are converted into high quality value added ash which unique secondary raw material due to the high amount of silica in the ash [9].

Rice straw and husk are composed of both organic and inorganic matter. Organic matter consists of cellulose, lignin, hemi cellulose, some proteins and vitamins while the major component of inorganic minerals is silica. The actual composition of rice straw and husk varies with the type of paddy, inclusion of bran and broken rice in the husk, geographical factors, crop season, samples preparation and relative humidity [10], [11].

This is a bio waste from the rice plant. The silica is absorbed from the ground and gathered in the straw where it makes a structure and is filled with cellulose. When cellulose is burned, only silica is left which is grinded to fine powder which is used as pozzolana. It can be seen that rice straw have about $15 \%$ ash after burn, thus for every $1000 \mathrm{~kg}$ of rice straw burnt $150 \mathrm{~kg}$ ash are produced [12]. 


\section{EXPERIMENTAL MATERIALS}

\section{A. Cement}

The cement used was ordinary Portland cement (OPC) of 43 grade conforming to IS: 8112-1989.

\section{B. Fine Aggregate}

One type of fine aggregate was used throughout the experimental work so as to keep the fine aggregate variable constant. The sand was collected from a local small stream from the flowing water which is generally used in most of constructions in near vicinity of this stream.

The sieve analysis was carried out in accordance with IS: 383-1970 for the fine aggregate. The results of the grading fits within the limits set out in IS: 383-1970 for grading zone-IV. The fineness modulus of the sand found to be 1.97 and specific gravity 2.43 .The silt and clay content of the fine aggregate is $2 \%$.

\section{Rice Straw Ash (RSA)}

Rice straw is an agricultural residue abundantly available in rice-producing countries. Locally available rice straws are taken. The straws were burned properly in a mud oven as used by the villagers for cooking until it fully transformed into ashes. After it the ashes were sieved by $300 \mu \mathrm{m}$. The sieved ashes were used in the cement mix as a partial cement replacement for making the mortar. The silicon oxide content found to be $62 \%$ in RSA as found by chemical analysis. Specific gravity of RSA used is 2.0 as per specific gravity test conducted according to the method prescribed in (IS: 4031 (Part 11) 1988) for cement. The sample of the RSA has been shown in Fig. 1.

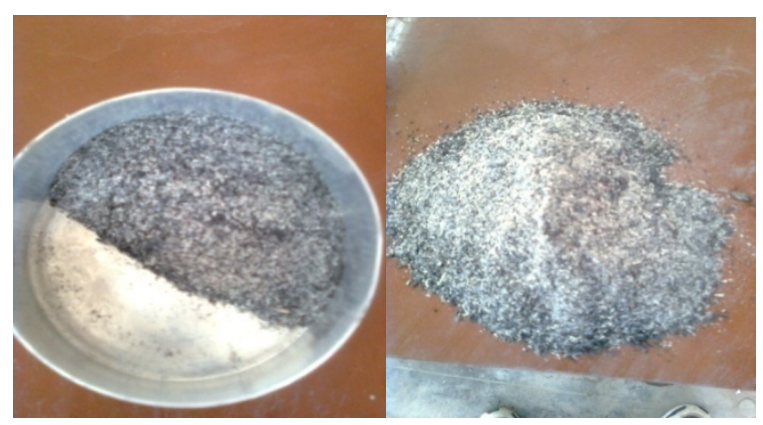

Fig. 1. Sample of RHA

\section{Water}

Locally available purified water was used in the present work.

\section{SAMPLE PREPARATION AND CURING}

Cement is partially replaced by RSA at a different percentage of $0,5,10$ and 15 by weight of cementitious materials. The rice straw ash and cement were first dry mixed in a pan properly so that a uniform mix of rice straw ash and cement is obtained. Fine aggregates were added together in the mixer. All materials mixed up in volumetric ratios. Cement mortar cubes of 1:3 proportions (cement and sand) were made with water cement ratio of $(p+12) / 100$, where $p$ is the normal consistency of cement.

Consistency of cement obtained $=36 \%$.

Water cement ratio $=0.48$

Then the water was added and the mix had been allowed thoroughly for rotating the mixer for more than two minutes.

Cubical specimens of $70.6 \mathrm{~mm} \times 70.6 \mathrm{~mm} \times 70.6 \mathrm{~mm}$ as shown in Fig. 2 were prepared. After placing of the mix in the mould the specimens were finished smooth and after that it was vibrated. After 24 hours of casting specimens were demoulded and immersed in water. Different batches were adopted for different ages of curing. And the testing was done after curing of 7 days, 14 days and 28 days.

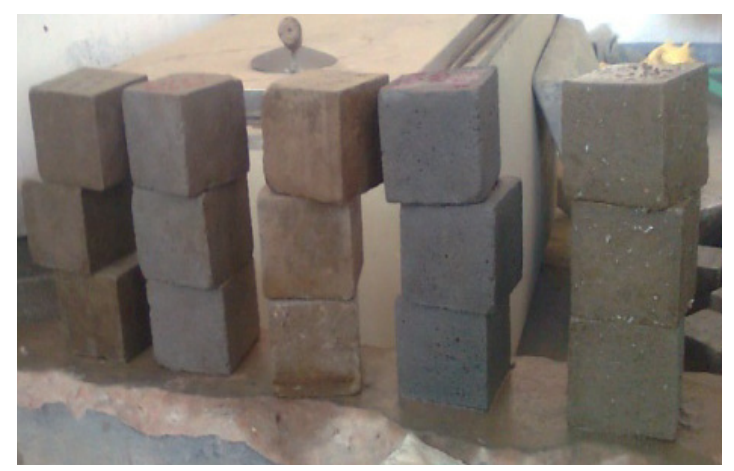

Fig. 2. Sample of cube casted for compressive strength testing.

\section{EXPERIMENTAL METHODS AND RESUltS}

\section{A. Grain Size Analysis}

The grain size analysis of RSA was done. The sieve sizes used are $300 \mu \mathrm{m}, 150 \mu \mathrm{m}$ and $90 \mu \mathrm{m}$ and $75 \mu \mathrm{m}$. After taking sample in the sieve, the sieve shaker was used for shaking purpose and after 15 minute sieves were removed from the shaker. The weights of the ashes retained in the sieve were taken.

The sieve analysis result of the RSA is shown below in Table I.

\begin{tabular}{llll}
\multicolumn{4}{c}{ TABLE I: GRAIN SIZE ANALYSIS OF RSA } \\
\hline $\begin{array}{l}\text { Sieve } \\
\text { no }\end{array}$ & $\begin{array}{l}\text { Percentage } \\
\text { retained }\end{array}$ & $\begin{array}{l}\text { Cumulative percentage } \\
\text { retained }\end{array}$ & $\begin{array}{l}\text { Percentage } \\
\text { passing }\end{array}$ \\
\hline $300 \mu \mathrm{m}$ & 10.07 & 10.07 & 89.93 \\
$150 \mu \mathrm{m}$ & 23.68 & 33.75 & 66.25 \\
$90 \mu \mathrm{m}$ & 20.1 & 53.85 & 46.15 \\
$75 \mu \mathrm{m}$ & 20.69 & 74.54 & 25.46 \\
pan & 25.46 & 100 & 00 \\
\hline
\end{tabular}

Further the particle below $75 \mu \mathrm{m}$ sizes retaining on the pan tested by hydrometer test. The test results of the hydrometer represented in the graph below in Fig. 3.

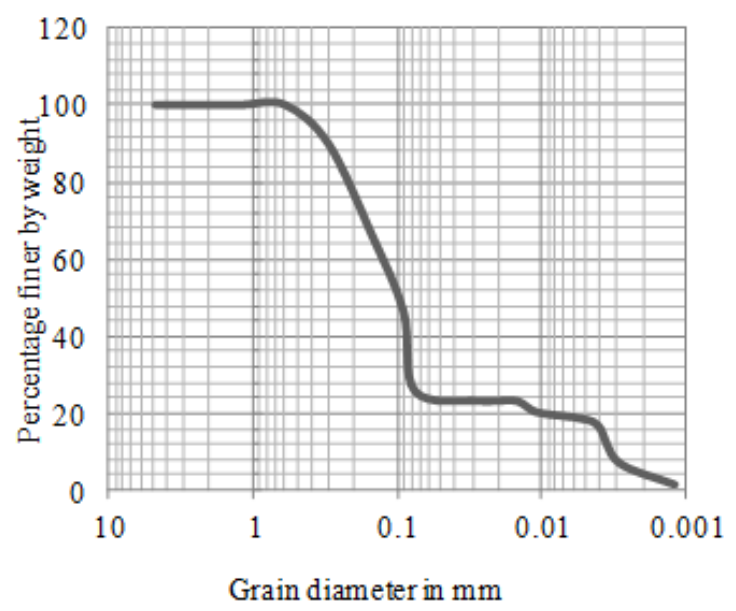

Fig. 3. Grain size analysis of RSA by hydrometer test. 


\section{B. Initial and Final Setting Time}

The term setting of cement is used to describe stiffening of cement paste. When the cement is mixed with water, the three main compounds of cement i.e., tri-calcium silicate $\left(\mathrm{C}_{3} \mathrm{~S}\right)$, tri-calcium aluminate $\left(\mathrm{C}_{3} \mathrm{~A}\right)$ and di-calcium silicate $\left(\mathrm{C}_{2} \mathrm{~S}\right)$ react with water. $\mathrm{C}_{3} \mathrm{~S}$ hydrates more rapidly and develop early strength, generates heat more rapidly and has less resistance to chemical attack. Whereas $\mathrm{C}_{2} \mathrm{~S}$ hydrates and hardens slowly and it adds to the ultimate strength and provides more resistance to chemical attack. $\mathrm{C}_{3} \mathrm{~A}$ is fast reacting and large amount of heat generates and cause initial setting. The phenomenon of changing from fluid state to a rigid state is called setting of cement.

Ordinary Portland cement of $300 \mathrm{gm}$ (W) accurately having standard consistency $(\mathrm{P})$. The water which is to be added in the above weighed cement is 0.85 times the percentage of water required for the standard consistency i.e., 0.85 PW. Cement and water were uniformly mixed with the spatula over a glass plate. The mixing or gauging time of cement and water is kept between 3 minutes 5 minutes. It is counted from the instant of adding water to dry cement up to the filling of the mould.

The cement paste as prepared was filled in Vicat's mould. Smoothened off the upper surface of the paste, to make it level with the top of the mould. There are two types of needle, one for initial setting and another for final setting time. For determining initial setting time put the initial setting needle and lower the needle gently in contact with the surface of the test block and quickly release the needle allowing it to penetrate into the test block. In the beginning the needle will completely pierce the test block. Repeat this procedure until the reading becomes $5 \pm 0.5 \mathrm{~mm}$, measured from the bottom of the mould. The initial setting time was noted. And for final setting time put the final setting time needle in the Vicat apparatus and release the needle gently as discussed above, till the needle makes an impression thereon. The period elapsing between the time when water is added to the cement and the time at which the needle makes an impression on the surface of the test block while the annular attachment fails to do so shall be the final setting time. The time recorded is presented in the observation Table II and according it has been represented graphically in Fig. 4.

TABLE II: Initial AND Final Setting Time at Different Percentage

\begin{tabular}{ccc}
\multicolumn{3}{c}{ OF RSA } \\
\hline Mix symbol & Initial setting time (min) & Final setting time (min) \\
\hline OPC & 130 & 220 \\
RSA 5\% & 140 & 240 \\
RSA 10\% & 150 & 265 \\
RSA 15\% & 175 & 280 \\
\hline
\end{tabular}

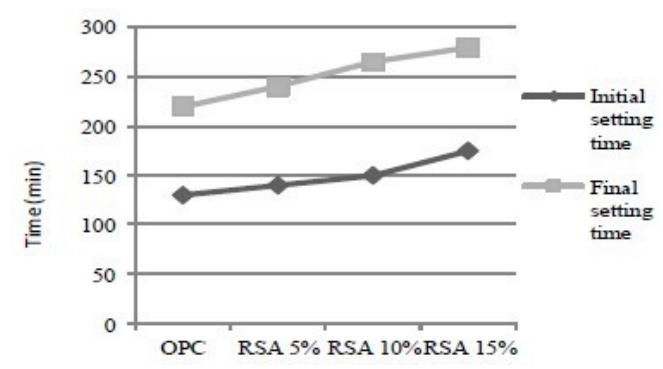

Fig. 4. Variations of initial and final setting time at different percentages of RSA.

\section{Compressive Strength}

Compressive strength is the capacity of a material or structure to withstand axially directed pushing forces. It provides data of force vs. deformation for the conditions of the test method. When the limit of compressive strength is reached, brittle materials are crushed. Compressive strength was tested by digital compression testing machine of $200 \mathrm{kN}$ capacity as shown in Fig. 5.

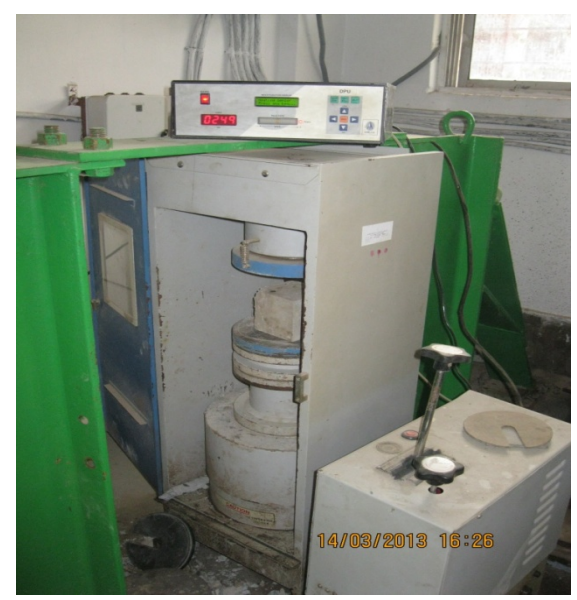

Fig. 5. Compression testing machine

The variations of compressive strength of cement mortar containing different percentage of RSA is shown in Table III:

\begin{tabular}{cccc}
\multicolumn{4}{c}{ TABLE III: COMPRESSIVE STRENGTH OBTAINED } \\
\hline \multirow{2}{*}{ RSA \% } & \multicolumn{3}{c}{ Compressive strength (MPa) } \\
\cline { 2 - 4 } & 7 days & 14 days & 28 days \\
\hline 00 & 13.04 & 18.00 & 28.00 \\
5 & 12.60 & 19.00 & 29.80 \\
10 & 12.60 & 20.00 & 32.00 \\
15 & 11.00 & 16.00 & 26.80 \\
\hline
\end{tabular}

The results of compressive strength obtained after 7 days, 14 days and 28 days from controlled specimen and specimen with different percentage of cement replacement with RSA have been represented below in Fig. 6 and Fig. 7.

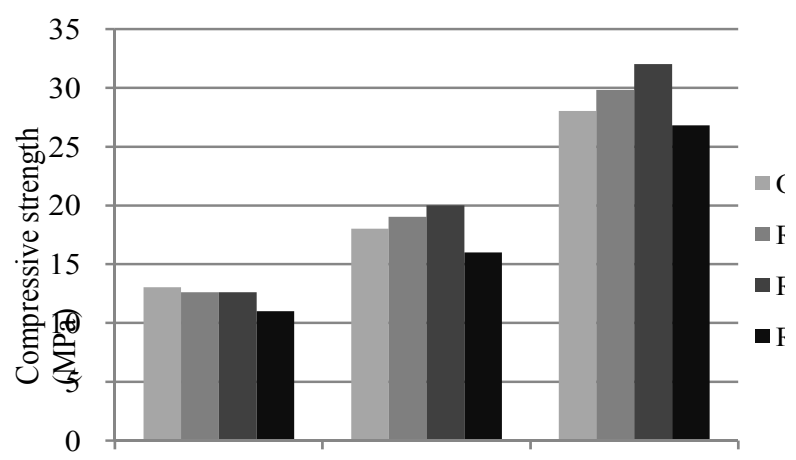

Fig. 6. Variations of compressive strength at different percentages of RSA

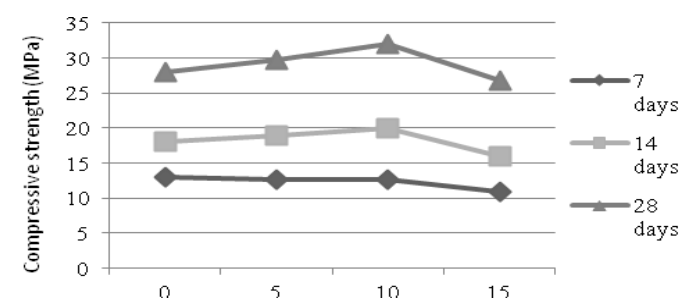

Fig. 7. Variations of compressive strength at different percentages of RSA 


\section{CONCLUSION}

Based on the experimental results of this study, the following conclusions were drawn:

The RSA increases the compressive strength up to $12.5 \%$, with $10 \%$ cement replacement in mortar with RSA.

The initial setting time and the final setting time are increased with the increased percentage of RSA replacement.

As the RSA is an agricultural residue and naturally available, it can lower the construction cost.

The result analyzed in this work presents, the influence of addition of RSA in the behavior of mortar is quite satisfactory. The use of RSA significantly improves the mortar strength and can be used as pozzolanic material in cement mortar. However, fine grinding and burning in controlled temperature may be required to get good quality RSA.

\section{REFERENCES}

[1] B. King, A Brief Introduction to Pozzolans. in: Alternative Construction - Contemporary Natural Building Methods, John Wiley \& Sons, London, 2000

[2] Specification for Fly Ash and Raw or Calcium Natural Pozzolona for Use as a Material Admixture in Portland Cement Concrete, ASTM C 618-78, American Standard for Testing Materials, 1978.

[3] G. C. Isaia, A. L. G. Gastaldini, and R. Moraes, "Physical and pozzolanic action of mineral additions on the mechanical strength of high-performance concrete," Cem. Concr. Compos., vol. 25, Issue 1, pp. 69-76, 2003.

[4] V. Papadakis, M. Fardis, and C. Vayenas, "Hydration and carbonation of pozzolanic cements," ACI Mater, pp.119- 130, 1992.

[5] B. March, R. Day, and D. Bonner, "Pore structure characteristics affecting the permeability of cement paste containing fly ash," Cem. Concr. Res. pp. 1027-1038, 1985.

[6] W. Al-Khaja, "Effect of sludge ash on the mechanical properties of concrete," Modell., Meas. Control pp. 9-14, 1997.

[7] S. Wild, J. Khatib, and A. Jones, "Relative strength, pozzolanic activity and cement hydration in superplasticized metakaolin concrete," Cem. Concr. Res. pp. 1537-1544, 1996.

[8] Md. H. Rashid, Md. K. A. Molla, and T. U. Ahmed, "Mortar incorporating rice husk ash: strength and porosity," European Journal of Scientific Research, vol.40, no. 3, pp. 471-477, 2010.

[9] Md. I. N. Morsy, "Properties of rice straw cementitious composite," Degree of Doctor of Engineering, Dept. Civil Eng. and Geodesy, Tecnische Universität Darmsta, 2011.

[10] D. F. Houston, "Rice hulls," in Rice chemistry and Technology, D. F. Houston, Ed. American Association of Cerreal Chemists, St. Oaul, Minnesota, pp. 301-352, 1972.
[11] V. M. H. Govindarao, "Utilization of rice husk- A preliminary analysis", J. Sci \& Ind. Res., vol. 39, pp. 495-515, 1980.

[12] Md. A. El-Sayed and T M. El-Samni, "Physical and chemical properties of rice straw ash and its effect on the cement paste produced from different cement types," J. King Saud Univ., vol. 19, Eng. Sci. (1), pp. 21-30, Riyadh, 2006.

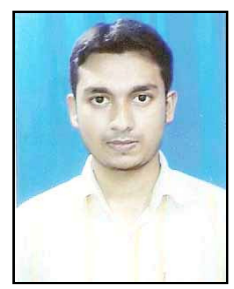

Surajit Munshi is a post graduate student under civil engineering dept. NIT Agartala. He was born in Tripura, India in 1988. He obtained Bachelor of Engineering degree in Civil Engineering from Tripura University, India. He is pursuing his Master of Technology in structural engineering at National Institute of Technology Agartala, Tripura, India.

His field of research interest lies in concrete technology and sustainable materials.

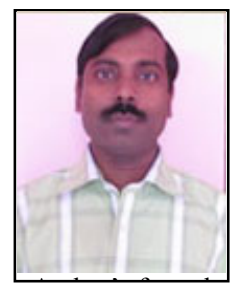

Gopinandan Dey is an Assistant Professor of NIT Agartala. He was born in Tripura, India in 1972.He obtained the B.E degree in civil engineering from Tripura University, India in 1994 and M.Tech degree in structural engineering from NIT Agartala, India in 2010.

He has a long stint of experience over 16 years as an academician and Engineer. He attended many conferences in India and abroad and has publications in International Journal. His field of research interest lies in concrete technology and sustainable materials.

Mr. Dey is a Life member of Indian Concrete Institute (ICI) and Indian Building Congress (IBC). He was awarded with Gold Medal in M.Tech.

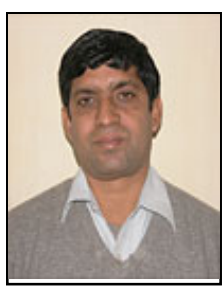

Richi Prasad Sharma is a professor of NIT Agartala. He was born in Tripura, India in 1962 . He obtained the B.E degree in civil engineering from Calcutta University, India in 1985, M.E degree in structural engineering from Bengal Engineering College, Shibpur, West Bengal in 1993 and Ph.D in 2003 from IIT Kharagpur, West Bengal, India.

He has a long stint of experience over 27 years as an academician and resercher. He has many publications in International Journal. His field of research interest includes study on dynamic friction, dynamic stability, blocky structural system, stability of slope and embankment and behaviour of concrete \& mortar.

Dr. Sharma is an affliated member of American Soceity of Civil Engineers (ASCE) and Fellow of Institution of Engineers (India). 